\title{
What remains, however improbable ...
}

\author{
The interpretation of the fossil remains of long-extinct creatures with no close modern relatives poses problems familiar \\ to fog-bound Victorians - and modern palaeontologists.
}

WHEN you have eliminated the impossible (said Sherlock Holmes), what remains, however improbable, must be the truth. Holmes was as logical as he was lonely sometimes, it is as if Conan Doyle's fictional Victorian detective represents the only rational beacon (apart from the faithful Dr Watson, of course) in a world in which fog-bound phantoms ever haunt the darker ends of the gas-lit streets, a district of opium dens, dogs that do not bark, the likes of Stevenson's Mr Edward Hyde, and virtually anybody from a Poe story. Palaeontologists know this neighbourhood well. They are quite used to working with fossils that defy interpretation, the remains of animals that somehow, even after everything else has been eliminated, seem to bend the pillars of the probable.

Such are the facts in the strange case of three tiny teeth from a well-known mammal fauna from the Early Cretaceous of Morocco, interpreted by their discoverer, Denise Sigogneau-Russell of the Institut de Paléontologie in Paris, France, as belonging to triconodonts, members of a long-vanished order of mammals (Acta Palaeontologica Polonica 40 (2), 149-162; 1995). One of the teeth, although with unusual, wickedly pointed cusps, resembles known triconodonts closely enough for it to be placed in that order with fair confidence, although it may represent a hitherto unknown family. SigogneauRussell names it Dyskritodon amazighi: the generic name - 'a tooth of uncertain placement' - reflects her understandable misgivings about her creation.

The other two teeth are far, far stranger. For, despite their each having paired roots (usually a good sign of a mammalian molar), they are thin and blade-like, rather than squarish and blocky. The cusps - three large ones with a smaller at the trailing edge - are deep, sharp and pointed. The whole affair looks less like a tooth than a miniature stoneage bone harpoon. They are clearly different from the sole tooth of Dyskritodon, but similar to each other, and SigogneauRussell corrals them both into the same species, Ichthyoconodon jaworowskorum. The generic name reflects a double meaning - these teeth look as if they come from a fish-eater, but they could also have come from a fish. Their phylogenetic placement, somewhere among the triconodonts, is even less certain than that of Dyskritodon.

Sigogneau-Russell spent much time eliminating the impossible before settling on the Triconodonta as the home for these improbable teeth. Even scolecodonts the microfossil jaws of worms - did not evade her scrutiny. Among vertebrates, her first call was among the fish, sharks in particular. Sharks (especially fossil ones) are unmatched in the novelty dentition department, but the presence of paired roots seemed to rule out Ichthyoconodon from their catholic membership. Again, the paired roots bar these barbs from the squamates (lizards, snakes - and other things). Dinosaurs (and they would have to be very petite dinosaurs) are unknown to have such teeth. Even pterosaurs, notorious for their outré orthodontics, cannot admit Ichthyoconodon to their be-fanged ranks. Among the mammals, SigogneauRussell examined the multituberculates. These Mesozoic mammals (extinct by the Eocene) sometimes have very specialized, multi-cusped teeth, but (among other things) the roots are not as well-separated as in Ichthyoconodon. So, triconodonts they are, at least for the time being.

The bulging casebook of masticatory mysteries shows that few things have such a memorable ability to sow confusion and dissent as teeth. Two years ago, in this column (Nature 360, 529; 1992), I discussed the debate about three teeth in a fragmentary jawbone from the Palaeocene of Canada, claimed by R. C. Fox et al. (Nature 358, 233-235; 1992) to have belonged to a member of a group of mammal-like reptiles otherwise extinct since the Jurassic. That claim has since been disputed, but until more of the skeleton of Chronoperates paradoxus is described, the mystery must remain unsolved.

The problem, in part, is that the design of teeth - at the sharp end, as it were, of the sustenance of the entire animal may say more about present function than past history. The naming of Ichthyoconodon as a fish-eater is wise, as fish-eaters of all kinds tend to have simple, pointed teeth that reveal little about ancestry. The teeth of toothed whales, for example, are far from the multi-cusped molars of their terrestrial progenitors. To choose another example, the rodents arguably owe their success as the most speciose mammalian order to their specialized dentition - the result is that rodent teeth all look much of a muchness to the uninitiated, making rodent systematics a formidable task. This problem makes the assignment of Ichthyoconodon to the triconodonts (or to anything else) a brave one.

A wider problem concerns the way in which palaeontologists, as comparative zoologists, interpret their fossils. One can make sense of a new specimen only by comparing it with material whose interpretation is already secure. Pleistocene palaeontologists have it easy, as most Pleistocene fossil forms have relatives alive today. Matters become harder as one goes back in time, to encounter forms that bear no close resemblance to anything now living. Such creatures hover at the dark end of the street. One thinks of the peculiar faunas of the Cambrian 'explosion' (see the report by Chen et al. on page 720 of this issue, with the accompanying News and Views by Stephen Jay Gould on page 681).

The twin problems of function and fossil interpretation collide with the conodonts. These phosphatic, tooth-like microfossils are sufficiently abundant in many Palaeozoic strata to be biostratigraphically informative, yet, until recently, the nature of the conodont-bearing animal was something to be guessed at. (Imagine the task of an alien palaeontologist of the future, trying to deduce the human frame from several million sets of dentures.) The discovery of the first body-fossils of conodont animals (D. E. G. Briggs et al., Lethaia 16, 1-14; 1983) did not immediately solve the problem, the animals being interpreted as chordates, chaetognaths, or molluscs with highly specialized shells. It now seems clear that conodonts were feeding structures of elongate, fish-like creatures closely related to vertebrates (P. Janvier, Nature 374, 761-762; 1995), although this interpretation has yet to receive universal approbation.

Swaddled in disorienting mist, palaeontologists live in a world beyond holmesian logic, perhaps closer to that imagined by another eminent Victorian: a landscape of dark frontiers peopled by borogoves, momewraths, mock turtles, and royalty quite happy to believe as many as six impossible things before breakfast. Henry Gee

\section{Correction}

John Maddox, in "Big Bang not yet dead but in decline" (Nature 377, 99; 1995), referred to results obtained by M. J. Pierce et al. using the Keck telescope. In fact their results were obtained at the CanadaFrance-Hawaii telescope, which is also in Hawaii. 